\title{
LA LIBERTAD DE ENSEÑANZA, TERRORISMO Y RESTRICCIONES ESTATALES: ¿CULTURA DE LA SOSPECHA O DEFENSA LEGÍTIMA DEL ESTADO?
}

FREEDOM OF TEACHING, TERRORISM AND STATE RESTRICTIONS: CULTURE OF SUSPECTED OR LEGITIMATE DEFENSE OF THE STATE?

EdWin Figueroa GutarRa*

Doctor en Derecho por la Universidad Nacional Mayor de San Marcos, Magíster en Derecho del Trabajo por la Universidad San Martín de Porres, Abogado por la Universidad San Martín de Porres, Juez Superior titular del Distrito Judicial de Lambayeque, Catedrático en los cursos de Derecho Constitucional, Derecho Procesal Constitucional, Docente en la Maestría de las Universidades Nacionales de Trujillo, Piura y Pedro Ruiz Gallo de Lambayeque, Autor de libros de Derecho Constitucional. 


\title{
LA LIBERTAD DE ENSEÑANZA, TERRORISMO Y RESTRICCIONES ESTATALES: ¿CULTURA DE LA SOSPECHA O DEFENSA LEGÍTIMA DEL ESTADO?
}

\author{
FREEDOM OF TEACHING, TERRORISM AND STATE RESTRICTIONS: CULTURE OF \\ SUSPECTED OR LEGITIMATE DEFENSE OF THE STATE?
}

Edwin Figueroa Gutarra

\begin{abstract}
RESUMEN:
A partir de un análisis entre las nociones de democracia y Estado constitucional, el presente estudio aborda las complejas relaciones entre el derecho fundamental a la libertad de enseñanza y el terrorismo. Es un eje de toda política pública combatir el terrorismo en el marco del Estado de derecho y en ese propósito, el Estado implementa restricciones estatales de no readmisión para profesores sentenciados por terrorismo. Sin embargo, resulta necesario dilucidar estas cuestiones respecto a si son expresiones de una cultura de la sospecha, o si en su caso constituyen medidas para una defensa legítima del mismo Estado.
\end{abstract}

\section{PALABRAS CLAVE:}

Democracia, democracia material, Estado de derecho, Estado constitucional, libertad de enseñanza, terrorismo, restricciones estatales, cultura de la sospecha, legítima defensa del Estado, monitoreo, test de proporcionalidad.

\begin{abstract}
:
Based on an analysis between the notions of democracy and the constitutional state, this study addresses the complex relationships between the fundamental right to freedom of education and terrorism. It is an axis of all public policy to combat terrorism within the framework of the rule of law and in that purpose, the State implements state restrictions on non-readmission for teachers sentenced for terrorism. However, it is necessary to elucidate these questions as to whether they are expressions of a culture of suspicion, or whether in their case they are measures for a legitimate defense of the same State.
\end{abstract}

\section{KEY WORDS:}

Democracy, material democracy, Rule of Law, Constitutional State, freedom of education, terrorism, state restrictions, culture of suspicion, legitimate defense of the State, monitoring, proportionality test.

\section{INTRODUCCIÓN}

Desde los valores materiales garantistas que sugiere Luigi Ferrajoli, el Estado constitucional tiene la facultad de organizar las medidas más adecuadas para combatir el terrorismo, problema contemporáneo que demanda acciones efectivas de los Estados para una efectiva defensa de los derechos fundamentales. El asunto que aludimos es complejo: el terrorismo como fórmula de acción antidemocrática, aprovecha los mecanismos de la democracia y mina las bases de ésta, situación que obliga al Estado a adoptar medidas de represión.

La cuestión a problematizar reside en cómo se deben efectivizar esas medidas sin afectación del derecho fundamental a la libertad de enseñanza de los profesores sentenciados por terrorismo, 
quienes frente a las decisiones del Estado de no readmisión de los mismos cuando pretenden regresar a enseñar, plantean una cuestión sustantivamente compleja: de un lado existe el derecho a la libertad de enseñar, y de otro, resulta necesario combatir el terrorismo con las armas constitucionales que provee la propia democracia. Estos temas nos conducen a un escenario en el cual ambos elementos deben ser dilucidados desde la perspectiva de que el Estado necesita cuidar los valores de la enseñanza y que éstos no se vean afectados por sentenciados por terrorismo, en específico profesores que pretendan regresar a las aulas, una vez cumplidas sus penas privativas de libertad.

En el caso peruano, el Estado ha dispuesto que los profesores sentenciados por terrorismo no puedan volver a enseñar. Se trata de una medida especial en defensa del derecho del alumnado a no contaminarse con un pensamiento proclive a la violencia que es muy difícil de erradicar. Lo usual es que un condenado que cumple altas penas por terrorismo, no se aleja totalmente del pensamiento violentista y ése es un baremo que es importante combatir con las armas materiales que provee la democracia.

Sin embargo, la cuestión controversial se suscita cuando el profesor condenado por terrorismo ha cumplido su pena y sin que su caso judicial haya previsto medida adicional alguna, se vea impedida dicha persona de volver a enseñar, cuestión que puede entenderse, en apariencia, como una prolongación inconstitucional de la pena, y al mismo tiempo, como asunto contrario al derecho fundamental a no ser sancionado más allá de lo que la misma pena establece.

La interrogante a determinar al respecto es: si el Estado restringe respecto de esta persona su derecho a volver a enseñar cuando la decisión judicial no ha previsto medida alguna adicional al respecto, ¿viola el Estado el derecho fundamental a enseñar o se trata de una acción legítima del Estado para defenderse de la posibilidad de una cultura de violencia en la que puede incurrir nuevamente esa persona sentenciada por terrorismo?

Nuestra propuesta en este estudio parte de la idea regular de que el Estado sí puede sancionar a los condenados por terrorismo, pero esto no se puede realizar extendiendo la pena cumplida más allá de lo que la misma establece, pues ello representa afectación severa de los derechos fundamentales de quien cumplió su pena y, válidamente, el sistema legal no puede extender la pena más allá de los criterios previstos por la ley.

Por tanto, se hace necesario implementar sistemas ex post o posteriores, de fiscalización y control de la actividad de los profesores sentenciados por terrorismo, en el caso que estos volvieran a enseñar, los cuales denominamos de monitoreo. Aquí corresponde realizar una división conceptual: las medidas ex ante, o sea previas, sin examen y en rigor fuera del contexto mismo de la pena aplicada, son inconstitucionales, pues parten de la noción de extender la pena más allá de lo que la misma prevé. Esto puede derivar en temas de responsabilidad internacional del Estado.

Sin embargo, un sistema ex post es compatible con el orden constitucional, en cuanto el Estado sí permite al profesor sentenciado por terrorismo volver a enseñar, a fin de no extender inconstitucionalmente la vigencia de la pena impuesta, pero en rigor implementa un sistema ex post o posterior que busca prever que el profesor no vuelva a difundir su pensamiento violentista. Desde esta perspectiva, es viable que el Estado plantee un sistema de monitoreo, a través del cual ejerza control, a través de monitores- profesores asignados para participar en las clases del profesor sentenciado por terrorismo, o bien en su caso a través de sistemas audiovisuales de grabación de las clases- y es a través de dicho sistema que se ejerce una constatación ex post respecto a la actividad del profesor readmitido en la enseñanza.

De esta forma, si el profesor- monitor o sistema audiovisual corroborara que el profesor sentenciado por terrorismo, incurre nuevamente en la difusión de ideas de una práctica violentista, 
pues son necesarias administrativamente las sanciones del caso, y de corresponder, será razonable la expulsión, conforme a ley y a la Constitución, de ese profesor de la carrera educativa.

El sistema que proponemos goza de asidero constitucional, en cuanto es compatible con los derechos fundamentales. En propiedad implica mayores recursos para el Estado, pues ciertamente habrá que implementar estas medidas, y sin embargo, el concepto de vigencia del Estado constitucional, impone cargas legítimas a los Estados parte de un sistema. ¿Cómo se entienden estas cargas legítimas? Como medidas necesarias, que implican recursos por cierto, pero que se inscriben dentro de la necesidad de dar respuestas congruentes, proporcionales y adecuadas a los contextos de posible afectación de los derechos fundamentales de quienes han incurrido en prácticas violentistas, las cuales deben ser reprimidas, más dentro de los principios, valores y directrices del Estado constitucional.

El Estado tiene derecho a defender los valores que dan vida a la convivencia social, de un lado, y necesita, por otra parte, realizar su condición de Estado como ente social, en donde los derechos a la igualdad sean respetados en su ámbito material, es decir, de esencia y núcleo duro de los derechos de las personas. Esa práctica, que debe aspirar a realizar el valor igualdad, requiere entonces de medidas adecuadas para la realización de ese fin.

Un profesor sentenciado por terrorismo falta a sus valores al deber de enseñanza si en clases vuelve a difundir ideas violentistas. Nuestra idea reviste convicción al afirmar que se rompe la esencia del deber de educar si el maestro difunde la idea de que el terrorismo es un medio de realización del bien social. Bajo esas condiciones, el Estado está facultado a actuar para defender los valores del Estado constitucional- vigencia irrestricta de los derechos fundamentales y primacía normativa de la Constitución- más la exigencia moral, dentro de los postulados de Ronald Dworkin y Robert Alexy, significa, también, reconciliar el Derecho y la Moral para asegurar un equilibrio en las relaciones sociales.

De esa forma, creemos que el Estado constitucional debe asumir las cargas legítimas que le corresponden y como tal, le es inherente la adopción de medidas necesarias dentro de un sistema de respeto por los derechos de las personas. Sancionemos lo que haya que sancionar, más dentro de los límites materiales que nos imponen nuestras Cartas Fundamentales.

\section{DEMOCRACIA Y ESTADO DE DERECHO}

La noción de democracia material ${ }^{1}$ representa en este siglo XXI una conquista del Estado constitucional. El tránsito del Estado legislativo de derecho, propio del siglo XIX, hacia un Estado constitucional de derecho, arraigado hacia finales del siglo XX y enraizado hacia inicios del siglo XXI, ha supuesto la consolidación del valor de la democracia, forma de Estado que con Norberto Bobbio y Giovani Sartori, nos remite hacia los valores de convivencia social necesarios en el Estado contemporáneo, cuya fórmula del Estado de derecho representa la consecución de una vigencia efectiva de los derechos fundamentales y del principio de primacía normativa de la Constitución.

La democracia, por consiguiente, representa un estadío que recoge diversos valores: ajusta los estándares de la cultura de la fuerza, controla los excesos del poder a través del control constitucional, y desarrolla fórmulas de defensa de los derechos de los ciudadanos. Atrás quedan las tiranías y las desviaciones del poder, y es través de la democracia que se consolida un sistema de gobierno que aún con sus carencias, representa la forma más óptima de convivencia social.

La idea más cercana a la noción de democracia material que planteamos se vincula a la idea de democracia sustancial que defiende Luigi Ferrajoli, para quien ésta última es una de las formas de expresión de la democracia constitucional, en referencia a los derechos primarios, relativos al qué se decide, relacionados con los derechos individuales y sociales. 
El uso de términos justos nos obliga a realizar una precisión: no es la democracia en sí el mejor sistema de gobierno, preferimos usar en su lugar la referencia al sistema más óptimo de gobierno, y esto tiene una explicación en cuanto no existe en rigor una mejor forma de gobierno y por exclusión, que las demás sean peores formas de gobierno. En ese orden de ideas, es importante puntualizar que todos los sistemas de gobierno presenta fortalezas y carencias, mas es la democracia, dentro de ese mecanismo de distinción, el concepto que nos remite a un número más amplio de escenarios favorables para los derechos fundamentales, frente a un conjunto de carencias que los gobiernos de la fuerza- los Machtstaat- (Zagrebelsky, 1995, p.21) exhiben en mayor grado.

La democracia, entonces, al representar una forma más óptima de gobierno, admite en esta definición, el reconocimiento de contravalores que la minan por dentro, y que por supuesto no la deslegitiman, sino tiende a convivir con ellos, en mayor o menor grado. Se trata de problemas que aquejan a la democracia y que por cierto la ponen a prueba. Así, la pobreza, la delincuencia, el narcotráfico y el terrorismo, entre otros grandes problemas sociales, son también manifestaciones de la democracia.

El concepto de Estado de derecho nos permite agregar al término democracia la idea de una llamada democracia material, en razón de la oposición convencional a la noción de democracia formal. Esta última nos remite a la sola idea de existencia de la democracia como tal, es un concepto lineal y uniforme de democracia, y solo exige el escenario de existencia de determinadas instituciones, entre ellas las de separación de poderes, la existencia de un ordenamiento jurídico y la configuración de un sistema jurisdiccional, en cuanto tal.

Sin embargo, una idea de democracia material, en alusión a los elementos antes citados, nos permite llegar a inferir la existencia de un equilibrio entre poderes, como elemento concomitante de una separación de poderes. De igual forma, si aludimos a la existencia de un ordenamiento jurídico, es importante tener en cuenta que en una democracia material existe compatibilidad entre estas normas y la Constitución. Por otro lado, en una tesis de apertura de la concepción de jurisdicción, tenemos un sistema en el cual se defiende con énfasis las necesarias relaciones de complementariedad entre justicia ordinaria y justicia constitucional.

¿Qué apreciamos de las ideas que anteceden? Pues que la democracia material representa un escenario importante de valores agregados respecto de la democracia formal, y ese conjunto de elementos intrínsecamente axiológicos precisamente se construye desde la fórmula del Estado de derecho, rango que representa la existencia, vigencia y compatibilidad de valores que se desprenden de la convivencia en una sociedad que respeta los valores que representan los derechos fundamentales, así como la cláusula de supremacía constitucional que en su momento enunciara, con énfasis, el leading case Marbury vs Madison. (Carbonell, 2006, p.298)

De otro lado, la democracia material, como producto del Estado de derecho, también se expresa en la noción de una democracia constitucional, idea que Elster (2002,p.111) prefiere graficar como la escena de un Ulises atado, y que si bien implica para el héroe aqueo poder escuchar los cantos de las sirenas al pasar la barca de aquel por Antemoesa, la peligrosa isla de éstas, estar atado al mástil significará no sufrir las consecuencias del ahogamiento, efecto natural para todo aquel marino que osaba escuchar los bellos cánticos de las sirenas y desesperado, se lanzaba al mar.

Lo descrito nos permite asimilar las ideas de un Ulises atado y una democracia constitucional. En ambos casos, hay sujeción, control y restricciones, necesarias para que en su caso, Ulises siga vivo, y de otro lado, para que la democracia represente una institución vigente en el Estado de derecho.

El problema se presentaría cuando el también llamado Odiseo se logra liberar de las cuerdas que lo atan al mástil de su embarcación. Si ello sucediera, bien podría morir ahogado al quedar embelesado por los cánticos mortales de las sirenas. 
Una democracia contemporánea, como en el caso de Ulises, puede sucumbir en forma figurada cuando no hace caso a sus propios controles, o de ser el caso, si los ignora por causas ajenas a sus estándares de control.

Así, bajo un ejemplo aproximado a esta figura, bien puede una democracia disponer, por el voto de la mayoría, archivar investigaciones por crímenes de lesa humanidad en aras de la reconciliación social, e invocando una necesidad de sembrar la paz social, más aún si los procesos de transición de los escenarios de conflicto hacia opciones de paz social, han sido traumáticos. Algo similar ocurrió en el caso Gelman vs Uruguay, ${ }^{2}$ en tanto una ley de cierre de investigación de crímenes en el año $1986^{3}$ en Uruguay, fue objeto de un referendo popular, el cual aprobó la norma sometida a consulta. En ese caso, la Corte Interamericana de Derechos Humanos ordenó al Estado uruguayo dejar sin efecto esa norma por contravenir principios recogidos por la Convención Americana de Derechos Humanos.

Es cierto que una ley aprobada por referendo goza de un status especial. No se trata de cualquier norma, pues es más que una ley ordinaria, cuya aprobación exige mayoría simple, y representa incluso mayor ámbito que las leyes orgánicas o de reforma constitucional, las cuales exigen mayorías calificadas. Por otro lado, se trata de una norma que, al haber sido aprobada en referendo, goza incluso de una condición aún más especial, en cuanto es el pueblo soberano quien ha adoptado la posición de avalar una decisión del Poder Legislativo.

Si el antiguo aforismo aseveraba que vox pópuli vox Deit representaba la consecución de la voluntad popular, es de notarse que desde la perspectiva del Estado de derecho, ese añejo adagio no va más, dado que en el Estado constitucional no hay zonas exentas de control constitucional y todo se ve impregnado por el Derecho Constitucional, así como existe un efecto de irradiación de la vigencia efectiva de los derechos fundamentales y del principio de primacía normativa de la Constitución.

Desde ese eje de razonamiento, es relevante tener en cuenta que las mismas decisiones del pueblo soberano se convierten en situaciones susceptibles de control constitucional. Podrá aseverarse, con cierta lógica, que en un referendo el pueblo ejerce la atribución de un poder constituyente derivado, en cuanto existe una voluntad formativa de aprobar una ley desde los predios de la votación universal. Podrá incluso sostenerse que en estos ámbitos de la democracia, el pueblo en votación universal representa una mayoría inescrutable, producto de una decisión universal, y sin embargo, la teoría del control constitucional hace posible la revisión de las decisiones incluso mayoritarias., desde el razonamiento de que no hay zona exenta de control constitucional.

En conclusión, la democracia al avanzar hacia un estadío de democracia material, representa la fórmula de conjugación de la democracia misma y el Estado de Derecho, mas no desde la posición fríamente silogística de la democracia formal, sino desde una visión dinámica de nuestra realidad. Es por esa razón que la idea de una living Constitution (Strauss, 2010, p.51) nos persuade de la dinámica de la democracia en todos sus ámbitos de influencia. La democracia material es, bajo estos parámetros, expresión de vida y sustento de una idiosincrasia en clave de fortalecimiento de los derechos fundamentales así como de la hegemonía de la primacía de la Constitución.

\section{DEMOCRACIA Y TERRORISMO: UNA RELACIÓN CONFLICTIVA}

En apariencia, existe una relación de exclusión entre democracia y terrorismo. La primera acepción representa la apertura de los derechos de los ciudadanos en la escena contemporánea, mientras

CORTE INTERAMERICANA DE DERECHOS HUMANOS Caso Gelman vs. Uruguay. Sentencia de 24 de febrero de 2011. Fondo y reparaciones.

3 Ley de caducidad de la pretensión punitiva del Estado, promulgada en 1986 por el gobierno democrático del Uruguay.

4 Aforismo entendido como "la voz del pueblo es la voz de Dios". Ya Nicolás Machiavelo se aproximaba a esta idea al sostener en su Discurso sobre Tito Livio la expresión: "La multitud es más sabia y constante que el príncipe." 
que el segundo concepto, el cual puede ser definido como una forma de criminalidad organizada y además una amenaza existencial,(Pérez, 2010, p.9) no es en modo alguno expresivo respecto a la progresividad de los derechos humanos. Sin embargo, muchas veces sucede que el terrorismo es consecuencia de los mecanismos que la propia democracia genera.

Una referencia breve a los ataques del 11 de setiembre de 2001 en Estados Unidos, nos permitiría concluir que esa incursión terrorista, aún con perspectivas dialécticas que aclarar en el contexto de la globalización misma, (Kellner,p.2) no hubiera sido posible sin el espíritu de apertura y confianza que en su momento impulsó el sistema norteamericano respecto al libre tránsito, casi irrestricto, de ciudadanos nacionales y extranjeros en su territorio. $O$ en su caso, que la misma planificación del ataque de terror no hubiere sido viable de llevarse a cabo, si no era por una libertad de comunicación sin espionajes anómalos por parte del poder público. Así, siendo EE.UU. una democracia que enarbolaba libertades y derechos, la confianza excesiva de los servicios de inteligencia de ese país devino en el resultado conocido: la caída de los Torres Gemelas en Nueva York y la muerte de casi 3,000 personas.

A su turno, los ataques terroristas en el teatro Bataclan en París en noviembre de 2015, no hubieran sido posibles sin esa apertura francesa por el incentivo de las artes en sus múltiples manifestaciones. A decir verdad, éste es un elemento común en toda democracia contemporánea, en cuanto desde el mismo Estado existe el aval de impulso a todas las facetas de la cultura, con la única atingencia de que no sean contrariadas la moral pública y las buenas costumbres. El terrorismo en este caso, como elemento de contradicción, capitalizó los elementos internos de las manifestaciones de arte en una democracia, para efectivamente reconducir contra ella, vía asesinatos indiscriminados, una actividad de odio, muerte y destrucción sobre vidas inocentes.

La afirmación anterior nos conduce a diversos escenarios, uno de los cuales es, en rigor, que la democracia genera espacios para diversas anomias. En efecto, el terrorismo es una actividad que finalmente infunde miedo, contrariedad y temor, pero precisamente uno de sus ejes de actuación es maximizar los vacíos que deja la democracia cuando ésta crece pero no puede desarrollar suficientemente mecanismos internos de autocontrol, resultando así como enuncia Reinares (1993) que el terrorismo resulte técnicamente más verosímil en regímenes de carácter tolerante que en otros de rasgos represivos (p.113). En adición a ello, el componente terror aquí es importante, según destaca Schmill (2003) al recoger una definición de Chomsky, en la medida que puede ser también definido como "el uso calculado de la violencia o la amenaza del uso de la violencia para alcanzar objetivos ideológicos, políticos o religiosos a través de la intimidación, la coerción o el miedo (p.37). En esa línea de reflexión, el terrorismo crece en las democracias constitucionales a pesar de los mecanismos de vigilancia que el Estado implementa.

Siguiendo los ejemplos que aludimos, incluso el terrorista capturado tras un ataque, goza de todos los derechos ciudadanos a la defensa, a un juicio justo y a un debido proceso, que la propia democracia enarbola como estandartes de los derechos ciudadanos, sin posibilidad de restricción de los mismos a ninguna persona por la sola condición de terrorista.

Entonces encontramos una manifiesta contradicción: el terrorismo capitaliza todo vacío posible de las democracias contemporáneas y establece sus estrategias de acción desde los mismos ejes de apertura de los derechos humanos en los ordenamientos jurídicos establecidos en el mundo occidental. Esto nos lleva a sostener una tesis muy puntual: la relación entre democracia y terrorismo no es de exclusión total sino de convivencia mutua, casi de producto uno de la otra, y de esa forma el terrorismo florece, se expande y desarrolla sobre los mecanismos de apertura de los ordenamientos jurídicos. Así, advertimos que las democracias tienen una mayor probabilidad, de resultar victimizadas por el terrorismo doméstico. (Oenema, p.24) 
Es de esa manera que donde los derechos constituyen las conquistas de rigor de los instrumentos normativos sobre derechos humanos- digamos la Convención Americana de Derechos Humanos y el Convenio Europeo de Derechos Humanos por citar los dos ejemplos más próximos a la escena occidental- es en esos ámbitos donde el terrorismo, definido como el sistema de quebrantamiento de los valores democráticos, aprovecha los mismos mecanismos de la democracia para minar los cimientos de ésta.

Ahora bien, si nos decantamos por afirmar que el terrorismo emerge en regímenes democráticos, no hay tampoco una relación de exclusión total en relación a las tiranías o respecto de sistemas de gobierno ajenos a la democracia. Sin embargo, la relación de grado es ostensible y con ello nos referimos a que en las democracias, los movimientos terroristas germinan con más facilidad, en tanto que en las tiranías precisamente el no respeto de los derechos humanos, mecanismo que suele expresarse en forma extendida en los ámbitos jurídico, social e institucional, hace mucho más difícil, aunque no imposible, el desarrollo de los movimientos terroristas.

Sin perjuicio de lo afirmado, tampoco existe una relación excluyente entre terrorismo y tiranías, pero resulta además cierto que en regímenes no democráticos, el arrasamiento de derechos es de efecto total sobre todos los ciudadanos, incluidos los elementos terroristas. De esa manera, será usual que en esos regímenes un ciudadano pueda ser afectado en su libertad individual de manera arbitraria, pero ello también podrá suceder con el terrorista. Así, no existirán garantías para ningún estamento social.

\section{LA LIBERTAD DE ENSEÑAR Y TERRORISMO: UNA CUESTIÓN COMPLEJA}

El derecho a la educación constituye uno de los derechos contemplados tanto por la Declaración Universal de los Derechos Humanos ${ }^{5}$ como por la Declaración Americana de Derechos Humanos ${ }^{6}$, y su manifestación principal reside en la no restricción de la persona a gozar del acceso a la educación. Junto a ese contenido base del Estado de Derecho, coexiste otra manifestación importante y lo es la enseñanza. Ciertamente si existe un derecho a educarse, su manifestación implícita lo es que sea un profesor quien enseñe, y ello se entiende como la libertad de enseñanza ${ }^{7}$, también denominada libertad académica.

Conceptualmente señala la UNESCO que la libertad académica consiste en "la libertad de enseñar y debatir sin verse limitado por doctrinas instituidas, la libertad de llevar a cabo investigaciones, difundir y publicar los resultados de las mismas, la libertad de expresar libremente la propia opinión sobre la institución o el sistema en que se trabaja, la libertad ante la censura institucional y la libertad de participar en órganos profesionales u organizaciones académicas representativas. Todo el personal docente de la enseñanza superior deberá poder ejercer sus funciones sin sufrir discriminación alguna y sin temor a represión por parte del Estado o de cualquier otra instancia"

Si bien la libertad de cátedra es una manifestación de la libertad de enseñar y se ciñe más al ámbito superior de la educación, la noción central de la libertad de enseñanza se circunscribe a la potestad

$5 \quad$ Declaración Universal de los Derechos Humanos Artículo 26.

1. Toda persona tiene derecho a la educación. (...)

2. La educación tendrá por objeto el pleno desarrollo de la personalidad humana y el fortalecimiento del respeto a los derechos humanos y a las libertades fundamentales; favorecerá la comprensión, la tolerancia y la amistad entre todas las naciones y todos los grupos étnicos o religiosos, y promoverá el desarrollo de las actividades de las Naciones Unidas para el mantenimiento de la paz. (...)

6 Declaración Americana de los derechos y deberes del hombre

Artículo 12 - Derecho a la educación Toda persona tiene derecho a la educación, la que debe estar inspirada en los principios de libertad, moralidad y solidaridad humanas. (...).

7 UNESCO. Organización de las Naciones Unidas para la Educación, la Ciencia y la Cultura. Recomendación No. 27 relativa a la condición de personal docente de la enseñanza superior. Adoptada el 11 de noviembre de 1997 en la Conferencia General de la Organización de las Naciones Unidas para la Educación, la Ciencia y la Cultura (UNESCO), reunida en París del 21 de octubre al 12 de noviembre de 1997. 
de enseñar sin mayores restricciones que las contempladas por la ley y la Constitución. En adición a ello, este derecho tiene lugar en todos los ámbitos de la educación. Una democracia material cuida que esta libertad de enseñanza se ejerza en todos los niveles- primaria, secundaria y superiorsin restricciones manifiestas dado que se encuentran vinculados dos derechos fundamentales: el derecho a la educación y la libertad de enseñanza.

La vinculación positiva de estos derechos se expresa en el resultado de un alumnado que es preparado con fortalezas, competencias y habilidades para el futuro. Sin embargo, también existe una manifestación negativa cuando existen incompatibilidades entre ambos derechos o disonancias en el ejercicio de uno de estos derechos fundamentales. Nos referimos aquí, entre otros casos, a la situación específica de que existan falencias respecto a quien ejerce la libertad de enseñanza. Si ello ocurre por la causa de que quien enseña predica un credo violentista como lo es el terrorismo, entonces tiene lugar una patología educativa, pues no logra la enseñanza el fin primordial de preparar y crear competencias en el alumnado, sino tiene lugar la impartición de una prédica violentista asociada a difundir ideología basada en prácticas contrarias a los fines de la democracia material.

La consecuencia lógica de este escenario es el quebrantamiento de los deberes de enseñanza que fluyen del contenido esencial de la libertad de enseñar, siendo una consecuencia perfectamente viable el procesamiento legal del profesor que incurre en la conducta típica del delito de terrorismo. A este respecto, debemos precisar que la represión de la conducta delictiva no necesariamente se va a asociar a la difusión de un credo violentista, tipo que podemos entender como la figura de apología del terrorismo, sino, las más de las veces, podrá ocurrir que el profesor sea procesado nuevamente por su pertenencia efectiva a grupos terroristas y su incursión activa en este tipo de movimientos.

Es importante poner de relieve que el profesor puede guardar reserva de sus ideas en clase. Esta conducta de suyo no es punible. Mas sí será antijurídica la acción vinculada a efectivizar el delito de terrorismo a través de acciones específicas contra la tranquilidad pública y la vida de personas inocentes. De ocurrir esto último, el Estado cumple su deber al detener, procesar, juzgar y sentenciar a quien hace real la prédica de daño que difunde el terrorismo.

El problema complejo a que apunta nuestro estudio reside en el escenario que tiene lugar cuando el profesor sentenciado por terrorismo ha cumplido su pena, ha pagado la reparación civil que impone la justicia penal, y pretende volver a enseñar. Más aún, la pena impuesta en el proceso penal no establece, en el caso que proponemos, que exista la prohibición de enseñanza una vez cumplida la pena. La situación a definir entonces tiene lugar de la siguiente forma: ¿puede el Estado en forma legítima prohibir al profesor sentenciado por terrorismo volver a enseñar?

Los escenarios posibles se bifurcan de la siguiente manera: si el Estado efectivamente prohíbe la enseñanza a este profesor sentenciado por terrorismo ¿no se produce acaso una indebida extensión de una pena extraordinaria que no fue contemplada en el proceso por terrorismo? Si la privación de libertad y el pago de la reparación civil ya han tenido lugar, ¿cuál es la justificación constitucional para extender la pena más allá de su contenido?

De la misma forma, si el Estado no fija restricción alguna y permite al profesor sentenciado por terrorismo volver a enseñar, ¿cómo previene que este profesor no pueda difundir sus convicciones, de ser el caso, respecto a una prédica violentista en desmedro del Estado de derecho? Nuestro esbozo de trabajo pretende abarcar estas dos opciones de examen del problema que planteamos y que exige una respuesta dentro de los principios del Estado constitucional, entendido como el tipo de Estado de derecho en el cual la salvaguarda de los derechos fundamentales es objeto de una debida ponderación, cláusula que se expresa en una exigencia previa de imparcialidad, condición característica en el examen de los derechos fundamentales. 


\section{RESTRICCIONES ESTATALES EN RELACIÓN A LOS TIPOS DE DELITOS}

Abarcar el estudio de las condiciones en las cuales el Estado puede en forma legítima irrogarse la facultad de restringir determinadas actividades a partir del tipo de delito que ha sido sancionado, puede constituir una tarea muy extensa, dado el número de bienes jurídicos que pueden estar involucrados. ${ }^{8}$ Sin embargo, haciendo un esfuerzo tentativo por agrupar diversos ámbitos de restricciones a partir de tipo de delito involucrado, podemos establecer prima facie tres rangos: los delitos vinculados a la indemnidad sexual de menores, los relacionados con el ejercicio del derecho fundamental a elegir y ser elegidos, y propiamente los casos de profesores sentenciados por terrorismo.

Respecto al primer caso, en relación a los profesores sentenciados por agresiones probadas contra la indemnidad sexual, consideramos que en el caso de la pauta sancionatoria de prohibirles a estos sentenciados volver a enseñar, la restricción se encuentra plenamente justificada. La afectación de la indemnidad sexual de un menor por parte de un profesor justifica la elevada sanción que implica la restricción de no volver a enseñar. En adición a ello, se prevé una conducta que a futuro podría repetirse y por consiguiente, podría extender el perjuicio físico, moral y emotivo hacia otros menores de edad. De suyo, el Estado ejerce en este caso una tarea de orden preventivo en cuanto previene que este tipo de conductas lesivas no se vuelva a producir.

Creemos que en este primer caso la tarea de restricción es legítima aún así la pena judicial no haya impuesto restricciones al respecto. Sobre lo mismo, la regulación restrictiva del Estado, sea a través de una norma con rango de ley o una disposición de carácter administrativo, es una herramienta idónea, necesaria y proporcional en sentido estricto, a efectos de establecer las restricciones del caso en la enseñanza de los profesores sentenciados por esta causa.

En un segundo orden de ideas, el derecho fundamental vinculado a la libre elección respecto a cargos públicos, presenta dos manifestaciones: el derecho a elegir y el derecho a ser elegido. Si una persona es sentenciada por terrorismo, el cumplimiento de la pena y el pago de la reparación civil habilitan a esta persona para recobrar su derecho a elegir. Aquí existe una simple recuperación de los derechos civiles y ello se traduce en que la extinción de la pena no puede ir más allá de sus propios límites, supuesto perfectamente viable en un Estado constitucional.

El dilema que se nos plantea sobre la legitimidad de la restricción del derecho a ser elegido, constituye una manifestación distinta del problema que no ocupa y nuestra propuesta tiene lugar por la inviabilidad de la restricción. Desde que el Tribunal Constitucional español fijara el criterio de una cultura de la no sospecha, ${ }^{9}$ el ejercicio de los derechos políticos no debe admitir más restricciones que aquellas que cumplan condiciones de razonabilidad y proporcionalidad.

De esta forma, no puede establecerse a priori una idea preconfigurada, irrazonable o inidónea, de que la sola elección de alguien sentenciado por terrorismo, pueda implicar la reincidencia en este mismo tipo de delitos. Una de las razones que justifica esta aseveración se vincula a la noción de que el sentenciado por terrorismo que eventualmente pueda ocupar un cargo en la función pública, no necesariamente debe implicar una sospecha velada de la sociedad en el sentido de que se defiendan ideas violentistas por parte de la nueva autoridad.

Al respecto, el derecho a la democracia es un componente siempre sensible para la sociedad en su conjunto, mas simplemente en base a esa misma noción, no puede un Estado predecir, desde un prejuicio formado, una sospecha formulada, o una suposición básicamente apriorística,

8 Si varios bienes jurídicos resultan afectados por una misma acción, debemos asumir que nos encontramos frente a delitos pluriofensivos. Ello conduce a un escenario de gravedad mayor.

9 Sentencia del Tribunal Constitucional español de 20 de junio de 2012. Caso Sortu. 
que necesariamente una autoridad elegida con antecedentes por terrorismo, vaya a incurrir en la misma conducta contraria a ley y a derecho.

El caso de los profesores sentenciados por terrorismo es un caso distinto a los dos antes enunciados, dados sus caracteres sui generis. El terrorismo finalmente implica conductas graves mas no en el mismo nivel de afectación de la indemnidad sexual de menores. De otro lado, la elección para cargos públicos en la materialización del derecho a ser elegido, recoge otro tipo de patrones pues ello implica el ejercicio de responsabilidades democráticas, de carácter representativo.

El propósito de los profesores sentenciados por terrorismo de pretender volver a la enseñanza, es absolutamente comprensible, dado que aspira a ejercer su derecho a la libertad de enseñanza, haya sido profesor de los niveles primaria, secundaria o superior. Más aún, constituye parte del contenido constitucionalmente protegido del derecho a la libertad de enseñanza que no exista arbitrariedad en el procedimiento de elección docente por parte del Estado cuando se trata de sancionar a quienes en su momento acogieron como credo político una práctica violentista y defraudaron, lo decimos con propiedad, la confianza del mismo Estado en la calidad de sus docentes.

Por consiguiente, es legítimo que el Estado a través de sus órganos de Administración, restrinja la libertad de enseñanza de los profesores sentenciados por terrorismo, dado que los mismos no solo han incurrido en una conducta típica, antijurídica y culpable sancionada por ley, sino porque reviste especial importancia que el terrorismo como delito contra la tranquilidad pública, igualmente constituye un tipo de patología social que merece las sanciones más severas, en cuanto pretende destruir los valores más representativos de la democracia, esto es, el respeto irrestricto por los derechos fundamentales, la existencia de una Constitución material como expresión del Estado de derecho, y el pluralismo de ideas, expresiones y tendencias políticas.

El quid del asunto respecto de lo que planteamos es cómo habría de ejercerse esa tarea de defensa de los valores de la democracia frente a los ciudadanos que equivocadamente abrazaron un credo violentista y que tras cumplir su pena, pretenden reincorporarse a la vida social pretendiendo ser readmitidos en la labor formativa, para cuyo efecto invocan la libertad de enseñanza como derecho fundamental.

Notemos aquí que un principio elemental del Estado constitucional es la interdicción de la arbitrariedad y como tal, dicha noción informa la relevancia de que el Estado mismo, frente a los derechos fundamentales, cumpla un deber especial de protección- Schutzpflicht- noción que debe ser asumida desde la perspectiva de que es obligación primordial del ente estatal, tutelar con más énfasis aún los derechos que tengan connotación iusfundamental. Y de allí la idea de que se trate de un deber especial de protección, en cuanto no es un deber ordinario, circunstancia que ocurre en el caso de un derecho de mera connotación legal, sino se trata de un derecho fundamental que reclama especial tratamiento normativo, fáctico y jurisprudencial por parte de los órganos que forman parte de la jurisdicción constitucional.

\section{TAREAS DE MONITOREO EN LA LIBERTAD DE ENSEÑANZA}

La exigencia de estándares óptimos en la calidad educativa orienta la actividad de todo Estado hacia una excelencia en la educación. De esa forma, el diseño de las políticas públicas en materia educativa, y por extensión formativa, demanda del Estado la implementación de reglas que perfeccionan los sistemas educativos y a partir de esta premisa, los entes estatales han de regular la actividad del profesorado en todos sus ámbitos, desde lo normativo, legal y administrativo, hasta regulaciones propiamente procedimentales en materia de recursos humanos y cuestiones colaterales para un adecuado ejercicio de las obligaciones que le competen al Estado mismo. 
La cuestión compleja a determinar es, dada esa producción normativa, cómo la misma, al regular restricciones, no incurre en afectación grave de los derechos fundamentales. En efecto, las reglas del debido proceso- el due process of law- son de especial importancia cuando se trata del Derecho Administrativo sancionador. De esa forma, el Estado tiene la facultad de sancionar como deber general, en referencia a la potestad de sanción, mas existe un deber específico de respetar, con especial énfasis, las reglas formales y materiales del debido procedimiento administrativo cuando de imponer sanciones se trata.

En desarrollo de esta idea, constituye exigencia para el Estado respetar reglas esenciales del debido procedimiento administrativo. Una de estas reglas es el principio de legalidad, en cuanto exige para la imposición de la sanción, junto al principio de taxatividad, los criterios base de lex previa, lex certa y lex scripta. De la misma forma, la sanción exige la observancia de los principios de razonabilidad y proporcionalidad, en la medida que la arbitrariedad implica un comportamiento a ser excluido cuando de derechos fundamentales se trata. De observarse estas reglas mínimas de legalidad y razonabilidad, podemos afirmar, con suficiencia, que la sanción es además de legal, también constitucional, e incluso convencional si nos referimos al respeto de los derechos humanos que contemplan los instrumentos internacionales como la Convención Americana de Derechos Humanos.

Diseñado ese marco, nos queda por definir cuál es el marco óptimo de acción del Estado si nos referimos a la idea de perfilar la necesidad de imponer sanciones a los profesores sentenciados por terrorismo una vez que éstos hayan cumplido su pena, pero al mismo tiempo, en el ejercicio de ese deber sancionador, se requiere que la actuación estatal sea respetuosa respecto de los derechos fundamentales involucrados en la materia a que hacemos referencia.

Pues bien, nuestra propuesta se orienta por la implementación de un sistema de monitoreo docente, el cual puede ser definido, desde la noción base de monitoreo como "la recolección de datos rutinarios para medir los avances hacia el cumplimiento de los objetivos del programa. Se utiliza para llevar un registro del desempeño de los programas a lo largo del tiempo, y su propósito es ayudar a los interesados pertinentes a tomar decisiones informadas respecto a la eficacia de los programas y el uso eficiente de los recursos." (Frankel, 2009, p.6)

Es importante diferenciar entre sistemas ex ante y ex post de fiscalización en relación a los casos que hemos referido. Un sistema ex ante suele implicar deficiencias tanto formales como materiales. Nos explicamos. La sanción ex ante, asumida como una sanción previa, tendería a afirmar que el profesor sentenciado por terrorismo, en forma taxativa, está impedido de volver a enseñar, a partir de la afirmación propia de la calidad del delito.

En nuestra opinión, este sistema es complejo pues no solo constituye una expresión de la cultura de la sospecha, aludido supra, criterio que puede ser extraído del caso Sortu, a partir del fallo emblemático del Tribunal Constitucional español en materia del derecho a formar organizaciones políticas, sino también resulta una conducta contraria a los derechos fundamentales, desde la noción de que un prejuicio no puede constituir un criterio ratio decidendi, premisa reafirmada por la Corte Interamericana de Derechos Humanos en el caso Karen Atala Riffo vs. Chile. ${ }^{10}$

Lo afirmado representa efectivamente un tema complejo frente a los derechos fundamentales en su concepción hoy vigente de derechos con un contenido material muy extenso. De prohibir la Administración del Estado que el profesor sentenciado por terrorismo vuelva a enseñar, observemos que será difícil aunque no imposible quizá, oponer un argumento constitucional de suficiente sustento para desestimar el cuestionamiento a que la pena se extiende indebidamente más allá de lo que estrictamente establece la sentencia.

10 Corte Interamericana de Derechos Humanos. Caso Atala Riffo y niñas vs. Chile. Sentencia de 24 de febrero de 2012 (Fondo, reparaciones y costas). 
En efecto, la principal objeción a superar por parte del Estado en una eventual demanda judicial de amparo contra la restricción estatal de la libertad de enseñanza del profesor sentenciado por terrorismo, será que en propiedad la pena no puede ser extendida más allá de los alcances que la misma impone. Esa situación en definitiva acarrearía inconstitucionalidad de la sanción administrativa en razón de extender más allá de la pena los límites restrictivos que impone por sí misma la sanción.

Si se tratare incluso de una ley expedida con anterioridad al cumplimiento de la pena impuesta al profesor sentenciado, albergaríamos incluso dudas respecto a la constitucionalidad de la norma misma, en cuanto las leyes pueden invocar necesidades de defensa del Estado frente a las amenazas a la democracia, y sin embargo, es necesario reafirmar que las restricciones estatales respecto al nivel de empleabilidad con relación a delitos cometidos, de suyo exigen compatibilidad con los principios, valores y directrices que informan toda Carta Fundamental. Más aún, la libertad de enseñanza se vincula estrechamente, incluso, al derecho fundamental al trabajo, de un lado, y a la libertad de trabajo misma, por otro lado, condiciones que exigen un comportamiento democrático del Estado frente a este tipo de situaciones.

Insistimos en un aspecto: las leyes de restricciones de los derechos vinculados a la libertad de enseñanza, la libertad de trabajo y el derecho fundamental al trabajo, no superan las exigencias de ser normas estrictamente necesarias si existe una opción menos gravosa que persiga y logre igualmente un fin de relevancia constitucional, pero que a su vez no sea tan onerosa como la norma misma de restricción de prohibición absoluta de enseñanza.

Nuestra propuesta consiste, entonces, en un sistema de monitoreo como norma de procedimiento ex post, frente a los casos que impliquen la readmisión de profesores sentenciados por terrorismo en la enseñanza.

Definimos este sistema de monitoreo bajo las siguientes pautas:

\subsection{Exigencia de un sujeto sancionado por terrorismo cuya pena haya sido cumplida a cabalidad.}

Esta atingencia es relevante pues el delito de terrorismo comporta una situación de especial trascendencia antidemocrática, en cuanto no solo constituye una conducta punible sino pretende lesionar los valores mismos de la democracia. En ese sentido, se trata de un antecedente especialmente grave que supone adoptar medidas de orden administrativo por parte del Estado si se pretende diseñar un sistema de restricciones.

\subsection{El monitoreo como sistema ex post de fiscalización.}

La referencia a un sistema de fiscalización es importante aquí en cuanto supone un conjunto de reglas de procedimiento, las cuales tienen lugar después que el profesor sentenciado por terrorismo hubiere cumplido integralmente su pena. El cumplimiento del principio de legalidad en un sistema de monitoreo nos conduce a la idea de que se trata de procedimientos que los Estados deben diseñar a partir de un conjunto mínimo de reglas.

¿Y por qué el énfasis en que se trate de un sistema ex post? Ello tiene lugar para excluir los criterios de cultura de sospecha o de configuración de prejuicios. Es contrario a los derechos fundamentales sancionar a una persona bajo la suposición de algo que pueda hacer a futuro. Excepción a este caso ocurre en las situaciones de tentativa de un delito, asunto muy distinto al que abordamos, en razón de que la tentativa exige actos de ejecución demostrativos de que hay una conducta delictiva inminente, y en rigor se trata de actos de preparación que manifiestan una conducta a hacer real. 
La sospecha o el prejuicio son circunstancias contrarias a los derechos fundamentales. No constituyen en realidad un ámbito de justificación sino de simple toma de posición, y sin embargo, expresan un alto rango de debilidad como argumentos pues no expresan con suficiencia la fuerza de la sanción a imponer.

\subsection{El monitoreo implica el concurso de un medio fiscalizador.}

Aquí ponemos de relieve que el Estado permite al profesor sentenciado por terrorismo volver a enseñar, mas esta aceptación no supone una situación de libre albedrío. No es así pues el Estado se reserva que otro profesor, que participe aleatoriamente en las clases del profesor readmitido, pueda evaluar el contenido académico de las clases del profesor sentenciado por terrorismo.

De esa forma, si ese profesor en evaluación cumple los fines de su tarea de formador de generaciones de estudiantes, y no reincide, esta vez por medio de la docencia, en la difusión de sus ideas violentistas, pues el fin del monitoreo ex post se habrá cumplido. Así es altamente probable inferir una resocialización del profesor monitoreado o sujeto a control.

De otro lado, si ocurre que el profesor sentenciado vuelve a incurrir en estas prácticas de defensa de concepciones violentistas, pues deberá tener lugar un procedimiento administrativo sancionador y por cierto, la sanción máxima podrá consistir en la expulsión del monitoreado de la carrera docente.

¿Hay arbitrariedad en el procedimiento de monitoreo? Consideramos que no. El derecho de defensa se encuentra garantizado en todo momento. El derecho a contradecir o impugnar una eventual sanción a causa de los deberes docentes, constatados en una acción de monitoreo, igualmente es objeto de tutela de tener lugar un procedimiento administrativo de sanción contra el monitoreado.

El ejercicio de esta potestad por parte del Estado constituye la observancia del principio de interdicción de la arbitrariedad, en cuanto las reglas del debido procedimiento administrativo son escrupulosamente respetadas, esto es, la sanción solo tiene lugar después de un procedimiento administrativo que respeta el derecho de defensa, de contradecir y de impugnar.

Ahora bien, nuestro concepto de monitoreo ha involucrado la variable ostensible de un profesor que en forma presencial desarrolla la importante labor de fiscalización de un profesor sentenciado por terrorismo que vuelve a las aulas a enseñar. Sin embargo, la tecnología es hoy un componente que no podemos soslayar. Nos referimos a la viabilidad de que las clases del profesor sentenciado por terrorismo puedan ser grabadas y esto constituya, también, una forma de fiscalización.

En nuestra opinión, esta opción de procedimiento no constituye invasión de la privacidad en el ejercicio de la libertad de enseñanza, pues recoge un procedimiento que implica un mecanismo de control razonable y que no afecta ostensiblemente los derechos fundamentales en juego a propósito de esta tarea de fiscalización.

\section{LA CONSTITUCIONALIDAD DE UN SISTEMA DE MONITOREO}

El test de proporcionalidad, como técnica de interpretación constitucional, constituye en el ordenamiento jurídico contemporáneo una óptima alternativa de control de compatibilidad de una regla compatible con la Constitución. De la concurrencia conjunta de los requisitos de idoneidad, necesidad y proporcionalidad en sentido estricto (Alexy, 2007, p.459), podemos llegar a la conclusión de que una norma es legítima, dado que esa expresada legitimidad implica su validez con respecto a la Carta Fundamental. De esa forma, no basta que hoy una norma solo tenga la condición de vigente, es decir, que haya sido discutida, aprobada, promulgada y publicada, sino que exige una especial 
armonía con la Constitución. Ello se logra, entre otras variantes de la interpretación de los derechos fundamentales y la primacía normativa de la Ley de Leyes, a través del test de proporcionalidad. A su vez, ausente uno de los requisitos de este test, la norma devendrá en inconstitucional.

El monitoreo, como alternativa de procedimiento, soporta el test de proporcionalidad a que podemos someter una norma de este tipo, dado que la exclusión prima facie, ex ante o a priori del profesor sentenciado por terrorismo de la función docente, sí constituye un anticipo de juicio que eventualmente puede resultar una conducta contraria a los derechos fundamentales.

A su vez, esta medida soporta el sub examen de idoneidad por cuanto el fin de relevancia constitucional se expresa en la figura de que se busca, a través de una medida de control como el monitoreo, la excelencia en la educación. En propiedad, un alumno con formación adecuada e idónea es un propósito importante en todo sistema educativo y la forma de llegar a ello demanda un conjunto de reglas, mecanismos o pautas de procedimiento para ese fin. Desde esa perspectiva, la actividad reguladora del Estado implica la adopción de normas cuyo fin exige, para aprobar esta sub regla de idoneidad, que la norma sea adecuada en relación a un fin de relevancia constitucional. En otros términos, la norma adoptada debe garantizar ese fin para el cual la norma es construida.

Un sistema de monitoreo cumple el fin de relevancia constitucional aludido, dado que a través de una modalidad de fiscalización directa- un profesor monitor en la propia clase del profesor sentenciado por terrorismo que ha sido readmitido en la enseñanza, o un sistema de grabación audiovisual de la clase- se garantiza una formación óptima de los alumnos. Es propio afirmar que el alumnado debe tener una formación que se oriente a destacar los valores de un sistema que permita la convivencia en paz, y ello se logra a través de los valores de la democracia material y no de las prédicas violentistas. Descritas estas atingencias, la norma de monitoreo soporta el test de proporcionalidad en su primera exigencia de idoneidad.

De la misma manera, cumple esta norma el sub examen de necesidad en razón de que un monitoreo constituye un sistema más garantista de los derechos fundamentales. En efecto, si el fin de relevancia constitucional es la excelencia en la educación, la cuestión inmediata a dilucidar es cómo se logra ese propósito y más aún, la opción a plantear debe ser respetuosa de los derechos fundamentales.

En concordancia con lo planteado, nuestra opinión se inclina hacia una excesiva onerosidad en la prohibición absoluta de enseñar al profesor sentenciado por terrorismo que pretenda su readmisión en la enseñanza. Es una alternativa de suyo onerosa pues constituye una modalidad lesiva del derecho fundamental a la libertad de enseñanza. Esta prohibición constituye una consolidación de la cultura de la sospecha en el sentido de una suposición a priori de que el sentenciado por terrorismo, ha de incurrir en la difusión de un credo violentista. Hemos de verificar aquí que este sistema ex ante expresa rasgos de inconstitucionalidad pues supone un prejuicio en la determinación de las capacidades del profesor.

De otro lado, si bien es cierto que el propósito de la resocialización en el cumplimiento de la pena se expresa en una reincorporación del sujeto penado a la sociedad, y que éste vuelva a constituir un elemento útil para el bien común, resulta una consigna lesiva asociar el tipo de delito a la inviabilidad de la reincorporación. El terrorismo es ciertamente uno de los delitos más perjudiciales en relación a la tranquilidad pública y por ende, de afectación a los valores de la democracia, y sin embargo, el Estado es uno de los primeros entes a ser llamados en el necesario respeto irrestricto a los derechos fundamentales de los ciudadanos. De no hacerlo por adoptar medidas lesivas a los derechos fundamentales, sus normas no solo pueden enfrentar problemas de constitucionalidad en los procesos de tutela de derechos de orden constitucional, sino que incluso pueden enfrentar problemas de convencionalidad, dado el caso en el cual una norma interna sea sometida a control de la jurisdicción supranacional. 
Por consiguiente, frente a una medida apriorísticamente lesiva como lo es la exclusión total de los profesores sentenciados por terrorismo en la enseñanza, constituye una medida menos lesiva el sistema de monitoreo que exponemos. Se cumple cabalmente, a juicio nuestro, el sub examen de necesidad, dado que éste busca la aplicación de la medida menos lesiva, entre las alternativas existentes, para la consecución de un fin de relevancia constitucional.

Dado el contexto de que se busca la excelencia en la educación en todo sistema educativo, es más gravosa la exclusión total del profesor sentenciado por terrorismo, por suponer un juicio ex ante con rasgos de contrariedad con la Constitución, frente a la alternativa ex post de un sistema de monitoreo, que igualmente busca la excelencia en la educación pero lo hace desde una perspectiva menos vulneratoria del derecho fundamental a la libertad de enseñanza.

Finalmente, la medida satisface los estándares del sub examen de proporcionalidad en sentido estricto, dado que en este examen jurídico que representa este componente del test, verificamos que dos derechos fundamentales se oponen con manifiesta claridad: el derecho fundamental a la libertad de enseñanza, en cuanto concierne al profesor sentenciado por terrorismo que aspira a ser readmitido en la enseñanza, y de otro lado, no solo es un fin de relevancia constitucional sino un derecho de la sociedad, y ello se expresa en la excelencia en la educación.

¿Qué plantea en este caso el sub examen de proporcionalidad en sentido estricto? Pues que de dos derechos fundamentales opuestos, determinemos los niveles de afectación y satisfacción de los mismos, siempre bajo la regla de la ley de la ponderación: a mayor afectación de un derecho, tanto mayor debe ser la satisfacción del derecho fundamental opuesto. (Bernal, 2003, p.227)

La afirmación anterior nos lleva a reconocer dos cosas: de un lado, la importancia de reconocer que un derecho puede resultar efectivamente afectado, pero para que haya proporcionalidad entre ambos, la satisfacción del derecho opuesto debe ser mayor. Esto no es una conclusión meramente discrecional sino que demanda en rigor la concurrencia de circunstancias fácticas y jurídicas que demuestren que el nivel de satisfacción de un derecho fundamental es mayor que el nivel de afectación del derecho fundamental en disputa.

Para ello, la doctrina del test de proporcionalidad ha previsto, vía una escala triádica, la existencia de tres niveles, tanto de afectación como de satisfacción: elevado, medio y débil.(Bernal, p.228) Si asignáramos valores numéricos a estos niveles, bien puede el valor elevado, implicar una hipotética determinación de 3 puntos, y su vez, el nivel medio, 2 puntos, así como el rango débil 1 punto. Contrastados los puntajes de la afectación y la satisfacción, se demandaría que el derecho satisfecho siempre tenga mayor valor que el derecho afectado.

En el caso que nos ocupa, consideramos que el derecho a la excelencia en la educación resultaría en parte afectado, pues en propiedad el respeto por los derechos fundamentales por parte del Estado, impide la vigencia y validez de una norma tan restrictiva como lo es la prohibición de enseñanza al profesor sentenciado por terrorismo en su propósito de ser readmitido en la enseñanza. Por tanto, el valor de afectación de este derecho es medio, y su rango numérico de valoración es 2.

A su turno, consideramos que el nivel de satisfacción del derecho a la libertad de enseñanza con suficiencia puede ubicarse en el nivel 3, dado que es elevada la satisfacción de este derecho a respetarse el contenido constitucionalmente protegido de la libertad de enseñanza, en razón de que no son admisibles decisiones arbitrarias por parte del Estado en su tarea de fiscalización de la educación. En este mismo sentido, el Estado tiene el deber de adoptar medidas constitucionalmente legítimas.

Si el valor de afectación del derecho a la excelencia en la educación es medio y de puntuación 2 , así como el nivel de satisfacción del derecho a la libertad de enseñanza es elevado y de puntuación 
3, podemos afirmar con suficiencia que la norma de monitoreo soporta el test de proporcionalidad y por consiguiente, es constitucional.

\section{CONCLUSIONES}

La democracia es un bien común que los Estados deben proteger no solo a través de Constituciones nominales o semánticas sino, en rigor, a través de políticas públicas cuyo eje sea el respeto efectivo de los derechos fundamentales y la primacía normativa de la Constitución.

El tránsito de ideas en este estudio ha sido darle forma a la compleja relación que suscita la acción del Estado frente a los profesores sentenciados por terrorismo que pretenden volver a la enseñanza. De por medio, se encuentran bienes jurídicos de trascendencia como el derecho fundamental a la libertad de enseñanza, al igual que las implicancias del terrorismo como seria amenaza contra la democracia.

Los Estados prevén así, en esa lucha sin cuartel contra el terrorismo, una serie de restricciones estatales como el impedimento de readmisión en la enseñanza a estos profesores sentenciados, mas en rigor existen rasgos de inconstitucionalidad en este tipo de decisiones, dado que se extiende, más allá de la pena que cumple el sentenciado por terrorismo, la represión por parte del Estado.

Hemos partido de la idea de que es necesaria la acción punitiva del Estado respecto a este tipo de delitos y sin embargo, esas decisiones estatales debe ser respetuosas del Estado constitucional en su fórmula de respeto a la vigencia efectiva de los derechos fundamentales y al principio de primacía normativa de la Constitución.

Dadas esas precisiones, hemos creído conveniente poner de relieve que el Estado no puede imponer una cultura de la sospecha o un sistema de decisiones basado en prejuicios. Esto ocurre, a juicio nuestro, cuando el profesor sentenciado por terrorismo no es readmitido en su propósito de volver a enseñar tras el cumplimiento de su pena. Calificamos esto como un sistema ex ante que adolece de inconstitucionalidad.

En consecuencia, proponemos un sistema ex post, o de monitoreo, que acepta la readmisión del profesor, pero a su vez el Estado adopta medidas de control efectivo, a través de un profesor monitor o bien a través de un sistema de grabación de las clases impartidas, en el único propósito de medir un desarrollo adecuado de las clases y de no aceptar la prédica en aulas de credos violentistas. Esta medida es una fiel expresión de legítima defensa del Estado constitucional.

Hemos incluido, a propósito de esta propuesta de monitoreo, un examen de la medida a través del test de proporcionalidad, técnica de interpretación constitucional que permite determinar la compatibilidad de una regla, norma o disposición con la Constitución. El resultado de dicho examen ha sido positivo y por consiguiente, demuestra la constitucionalidad de la medida, la cual per se no es invasiva sino se encuentra plenamente justificada, dados los bienes jurídicos en juego y las amenazas serias que representa el terrorismo.

Convenimos, entonces, en la necesidad de restricciones estatales frente al terrorismo mas estas decisiones exigen ser compatibles con los principios, valores y directrices que hoy informan las Cartas Fundamentales de todos los países del orbe. Se trata, a juicio nuestro, de cargas legítimas que hoy imponen las democracias a los Estados, y que en su propósito de concordancia y armonía con el bien común, exigen al Estado mismo posiciones que compatibilicen con los derechos fundamentales y con la primacía de la Constitución misma. Desde esa perspectiva, solo existe el Estado constitucional en la medida que exista una acción estatal permanente, continua y sostenida de protección real de los principios, valores y directrices de la Lex Legum. 


\section{REFERENCIAS}

- $\quad$ ALEXY, Robert. (2007). Teoría de la argumentación jurídica. Lima. Palestra Editores.

- $\quad$ BERNAL PULIDO, Carlos. (2003). Estructura y límites de la ponderación. En DOXA 26. CUADERNOS DE FILOSOFÍA DEL DERECHO. Universidad de Alicante.

- CARBONELL, Miguel. (2006). Marbury vs Madison: en los orígenes de la supremacía constitucional y el control de constitucionalidad. En: Revista Iberoamericana de Derecho Procesal Constitucional. N $N^{\circ} 5$

- $\quad$ CORTE INTERAMERICANA DE DERECHOS HUMANOS. Caso Gelman vs. Uruguay. Sentencia de 24 de febrero de 2011. Fondo y reparaciones.

- $\quad$ DURANGO ÁLVAREZ, Gerardo. (2007). Aproximaciones conceptuales a la democracia en la Teoría de L. Ferrajoli. En: Opinión Jurídica. Vol. 6, No. 12, Julio-Diciembre: Medellín, Colombia.

- ELSTER, Jon, (2002). Ulises desatado: las constituciones como restricciones. En: Ulises desatado: estudios sobre racionalidad, precompromiso y restricciones. Barcelona. Gedisa.

- KELLNER, Douglas. (s/f) Globalization, terrorism and democracy: 9/11 and its aftermath.

- Ley de caducidad de la pretensión punitiva del Estado, promulgada en 1986 por el gobierno democrático del Uruguay.

- OENEMA, Marianne. "The interaction between democracy and terrorism". En Social Cosmos.

- PEREZ ROYO, Javier. (2010). La democracia frente al terrorismo global. En: Terrorismo, democracia y seguridad, en perspectiva constitucional. AA.VV. Madrid. Marcial PonS.

- $\quad$ REINARES, Fernando. (1993). Estado, democracia liberal y terrorismo político. En: Revista del Centro de Estudios Constitucionales. Num. 16. Setiembre- diciembre.

- $\quad$ SCHMILL ORDOÑEZ, Ulises. Terrorismo y democracia.

- $\quad$ STRAUSS, David A. (2010). The Living Constitution. Oxford University Press.

- ZAGREBELSKY, Gustavo. (1995). El derecho dúctil. Ley, derechos, justicia. Madrid: Editorial Trotta. 